\title{
Outcome of Trans-obturator Tape Procedure in the treatment of Stress Urinary Incontinence at Kathmandu Model Hospital
}

\author{
Ranjana Shrestha, Ganesh Dangal, Sonu Bharati, Aruna Karki, Hema Kumari Pradhan, Kabin Bhattachan, \\ Rekha Poudel, Nishma Bajracharya, Kenusha Devi Tiwari \\ Department of Obstetrics and Gynecology, Kathmandu Model Hospital, Nepal
}

Received: May 8, 2020

Accepted: May 31, 2020

\section{ABSTRACT}

\begin{abstract}
Aims: To evaluate the improvement in the quality of life of women with stress urinary incontinence who were treated with trans-obturator tape procedure.

Methods: This is a cross-sectional study of treatment of stress urinary incontinence using trans-obturator tape at Kathmandu Model Hospital from February 2018 to December 2019. The outcome of the procedure in terms of improvement in quality of life and surgical complications were assessed.
\end{abstract}

Results: Out of 16 cases of stress urinary incontinence half of them were post-menopausal. One each had intra-operative bladder injury, urinary retention and urinary tract infection; 14 cases improved completely by a week, one had some improvement and one didn't improve. At six months follow-up one case had no improvement and one developed urge incontinence.

Conclusions: Trans-obturator tape has been found a good procedure for the treatment of stress urinary incontinence in our setting and hence led to high rate of improvement in quality of life with minimal and minor complications.

Key words: Complications; quality of life; stress urinary incontinence; trans-obturator tape

Citation : Shrestha R, Dangal G, Bharati S, Karki A, Pradhan HK, Bhattachan K, et al. Outcome of Trans-obturator Tape Procedure in the treatment of Stress Urinary Incontinence at Kathmandu Model Hospital. Nep J Obstet Gynecol. 2020;15(30):24-27. DOI: 10.3126/njog.v15i1.29335

\section{INTRODUCTION}

Stress urinary incontinence an unintentional, uncontrolled loss of urine through the urethra happens when vesical pressure exceeds the urethral sphincter pressure during coughing; sneezing or physical exertion. ${ }^{1}$ Any involuntary leak of urine is taken as incontinence according to the International Continence Society. ${ }^{2}$ Stress urinary incontinence (SUI) is the most common subtype of urinary incontinence in women. Incontinence in younger population has greater and longer impact in the quality of life; and SUI is the most amenable to available treatment being easy, safe and effective. ${ }^{3}$ Population-level prevalence data for developing countries are less readily available. SUI arises from the decreased support of the pelvic floor and vaginal connective tissue around the bladder neck and urethra. ${ }^{4}$ Urinary incontinence occurs in about of $20-30 \%$ of young women, $30-40 \%$ of middle age

\section{CORRESPONDENCE}

Dr Ranjana Shrestha

Department of obstetrics and gynecology, Kathmandu Model Hospital, Nepal

Email: ranjana_514@hotmail.com; Mobile: +977-9841817268 and up to $50 \%$ of women in old age. ${ }^{5}$ Trans-obturator tape (TOT) application procedure is done regularly at Kathmandu Model Hospital for last two years for the surgical treatment of SUI and its outcome has been shared.

\section{METHODS}

This cross-sectional study was carried out in the Department of Obstetrics and Gynecology at Kathmandu Model Hospital, Nepal during February 2018 to December 2019 after ethical approval. SUI was confirmed by physical examination. All cases with Stress/cough test and Bonney test positive with grade I/II cystocele were included in this study. Informed written consent was taken after explaining about the purpose, risk and benefit of the procedure. Urodynamic study was lacking at the facility. Trans-obturator tape insertion along with anterior 
colporrhaphy for cystocele (if present) was performed under spinal anesthesia at lithotomy position

Synthetic polypropylene mesh was inserted in the procedure as designed by Delorme. Vaginal pack and Foley's catheter were removed after 24 hours, and discharged after their first void. Immediate complications such as bleeding, bladder injury, and retention of urine during and after surgery were recorded and managed accordingly. Patients were followed up at one week and six months in person and via telephone call. Data management was done using SPSS software version 25.

\section{RESULTS}

Out of 16 cases of SUI, age range was 30-80 years; 8 were post-menopausal, 6 had cystocele and 11 were of three or more by parity [Table-1].

Table-1: Age, parity and menstrual status of women with stress urinary incontinence $(n=16)$.

\begin{tabular}{|l|c|c|}
\hline Variables & Age group & Frequency (\%) \\
\hline Age & $30-40$ & $4(25 \%)$ \\
& $41-50$ & $6(37 \%)$ \\
& $51-60$ & $3(19 \%)$ \\
& $61-70$ & $2(13 \%)$ \\
\hline Parity & $71-80$ & $1(6 \%)$ \\
\hline Menstrual status & 1 & $2(13 \%)$ \\
& 2 & $3(19 \%)$ \\
& Menstruating & $8(37 \%)$ \\
SUI with cystocele & & $5(31 \%)$ \\
\hline
\end{tabular}

One had chronic obstructive pulmonary disease. During TOT tape insertion one patient had bladder injury, for which immediately cystoscopy was performed, puncture site was identified for which Foley's catheterization was performed. On her $10^{\text {th }}$ post-operative day, dye test was performed and it was negative. After that Foley's catheter was removed.

During hospital stay, one patient had urinary retention following removal of catheter on her $1^{\text {st }}$ post-operative day for which re-catheterization was done. One patient developed urinary tract infection (UTI) on her $5^{\text {th }}$ post-operative and was treated with oral antibiotics.

During one week follow-up, one patient came with the complaint of no improvement in symptoms of SUI following trans-obturator tape treatment. At 6 month follow-up via phone call, all 14 cases had subjective improvement in quality of life, one developed urge incontinence but she was dry and had no improvement at all.

\section{DISCUSSION}

Majority of patient had improvement in quality of life and relieve of lower urogenital symptoms except with one patient with no improvement in quality of life even after 6 months of treatment. Most of the patients were satisfied with the treatment except two cases where one patient had complete relief of stress urinary incontinence symptoms but she developed urge incontinence and another had no changes in symptoms even after 6 months of the treatment.

Although SUI is not a life-threatening health concern, it affects approximately 200 million women and it influences the patients' social, psychological, occupational, domestic, physical, and sexual wellbeing. ${ }^{6}$

In a study done by Karl $\mathrm{M}^{7}$, specifically, older women were more likely to experience urge incontinence ( $70 \%$ among women $>60$ years versus $45 \%$ among women $\leq 60$ years) and younger women were proportionately more likely to experience SUI. This incidence was similar with our study where $60 \%$ women were of less than 60 years of aged suggesting that stress urinary incontinence is common in younger aged groups.

In a meta-analysis of 48 studies, Hampel and colleaguess reported similar results, estimating the prevalence of urinary incontinence to be $16 \%$ for women younger than 30 years and $29 \%$ for women aged 30 to 60 years. The investigators found SUI to be more common than urge urinary incontinence, with $78 \%$ of women having SUI versus $51 \%$ with urge urinary incontinence. In both studies, between $29 \%$ and $36 \%$ of women reported a combination of both stress and urge incontinence, or "mixed incontinence. $^{8}$

Some professional organizations recommend routine urodynamic testing before surgery for SUI, however, the National Institute for Health and Clinical Excellence advised against routine urodynamic testing before surgery in women with a clearly defined 
clinical diagnosis of pure stress urinary incontinence. ${ }^{9}$

In this study, success rate of treatment with transobturator tape was above $90 \%$ which was similar with the study done by UGuler and colleagues, suggested that Midurethral vaginal suspension surgeries are successful surgical methods that provide patient satisfaction rates of over $90 \%$ for stress urinary incontinence. The main measure of success is vaginal dryness and patient satisfaction. ${ }^{10}$

In 1995, Ulmsten and colleagues, first introduced the transvaginal tape (TVT) method. However, in 2001, the transobturator route was described by Delorme to reduce major complications, such as bladder and bowel injuries, related to the TVT procedure. However, fewer complications has been reported with TOT procedure such as bladder injury. ${ }^{10}$

TOT and TVT surgeries and Burch procedure constitute currently the most popular methods for surgical treatment of SUI. Regardless of the surgical method, the outcomes of the treatments are good. ${ }^{1}$

Mazma et $\mathrm{al}^{11}$ found that women's age and regional ethnicity distributions were associated with surgery rates. Adjusting for the women's age group and regional characteristics reduced variation only slightly. This may reflect differences in incontinencerelated health beliefs, preferences and care seeking behavior for older women and women from various ethnic backgrounds or inequitable use of surgical care. Studies suggest that only around half of older people seek help for their incontinence symptoms, commonly due to the belief that it is a normal part of ageing.
Another study revealed that the incidence of overactive bladder (OAB), both 3 and 6 months post-surgery, was the highest after Burch procedure (14.2\% and $17.5 \%$, respectively). The incidence of OAB documented at 3 and 6 months after TVT surgery was similar, accounting to $11 \%$. The complication turned out to be least frequent 3 and 6 months after TOT procedure, accounting to $4.6 \%$ and $7.4 \%$ respectively. ${ }^{10}$

Another multicentric randomized study confirms that TOT is as safe and effective in the surgical treatment of SUI as TVT. The overall objectives cure (dry) was $71.4 \%$ for TVT and $77.3 \%$ for TOT. ${ }^{12}$

In a multicentre study done by Krauth et al ${ }^{13}$ reported vaginal injury in 2 of 69 patients $(0.3 \%$ vs. our $2.8 \%)$. Bladder injury, the main concern with use of the retropubic route, occurred in 2 cases $(3 \%)$ in TVT group but is reported to have an incidence of up to $24 \%$ during TVT and Sparc procedures. ${ }^{14,15}$

One case of bladder injury has been reported in our study as complication but as a result of timely detection and the primary repair patient remained dry after continuous catheterization. No other major complications have been reported in our study, which may also be due to small sample size and inadequate long-term follow up.

\section{CONCLUSIONS}

Trans-obturator tape is a good and minimally invasive surgical procedure with high success rate by expertise urogynecologist. However, long-term follow-up is required to correctly report the case of recurrences.

\section{REFERENCES}

1. Sylwestar C, Kornel C, Agnieszka B, Magdalena P. Association between urinary bladder volume and the incidence of "De Novo" overactive bladder in patients with stress urinary incontinence subjected to sling surgeries or Burch procedure. BioMed Research international. 2019; Article ID 9515-242.

2. Downey A, Inmann R. Recent advances in surgical management of Urinary Incontinence. F1000 Research. 2019; 8(F1000 Faculty Rev):1294. DOI:https://doi.org/10.12688/ f1000research.16356.1.

3. Pandey D, Maturic, Dhaka BPS, Jain G, Kyalakand K. Intervention and Quality of Life in Stress Urinary Incontinence. Gynecol Minimum Invasive Ther. 2019; 8(3):106-12.

4. Youmaria W, Blayne W. Revisiting Current Treatment options for Stress Urinary Incontinence and Pelvic Organ Prolapse: a contemporary literature review. Res Rep Urol. 2019;11:179-88.
5. Gabriela K, Maciej Z, Krystyna R. Urinary Incontinence in Post-menopausal women. Menoapuse Rev. 2019;18(1):46-50. DOI: https://doi.org/10.5114/pm.2019.84157

6. Riza D, Iltac A, Bora C, Gamze D, Bugra C, Mehmet U, et.al. The Impact of Vaginal Cone Therapy on Stress Urinary Incontinence Compared with Transobturator Tape. Turk J Obstet Gynecol. 2019;16(3):169-73.

7. Karl M. The Definition, Prevalence, and Risk Factors for Stress Urinary Incontinence. Rev Urol. 2004;6(3):S3-S9.

8. Hampel C, Weinhold N, Eggersmann C, Thuroff JW. Definition of overactive bladder and epidemiology of urinary incontinence. Urology. 1997;50 (suppl 6A):4-14.

9. Nager CW, Brubaker L, Litman HJ, Zyczynski HM, Varner $\mathrm{RE}$, Amundsen $\mathrm{C}$, et.al. A randomized trial of urodynamic 
testing before stress -incontinence surgery. N Engl J Med. 2012;366:1987-97.

10. UGüler Y, Erbin A, Üçpınar B. Transobturator Tape material detected in the bladder neck: a case report. J Med Case Reports. 2019;13:119. DOI:https://doi.org/10.1186/s13256-0192059-y.

11. Mamza JB, Geary RS, El-Hamamsy D, Cromwell D, Duckett J, Monga A, et-al. Geographical variation in rates of surgical treatment for female Stress Urinary Incontinence in England: a national cohort study. BMJ open. 2019;9:e029878. doi:10.1136/ bmjopen-2019-029878.

12. Porena M, Constantini E, Frea B, Giannantoni A, Ranzoni S, Mearini L,et.al. Tension free Vaginal Tape versus Transobturator Tape as Surgery for stress urinary Incontinence: results of a Multicentric Randomized Trial. Eur Assoc Urol. 2007;52:1481-91.

13. Krauth JS, Rasoamiaramanana H, Barletta H, Grisard AM, Lienhart J, Mermet J, et al. Suburethral tape treatment of female urinary incontinence - morbidity assessment of the trans-obturator route and a new tape (I-STOP): a multi-centre experiment involving 604 cases. Eur Urol. 2005;47(1):102-6.

14. Minaglia S, Ozel B, Klutke C, Ballard C, Klutke J. Bladder injury during transobturator sling. Urology. 2004;64:376-8.

15. Andonian S, Chen T, St-Denis B, Corcos J. Randomized clinical trial comparing suprapubic arch sling (SPARC)and tension-free vaginal tape (TVT):one-year results. Eur Urol. $2005 ; 47: 537-41$. 